\title{
Atherosclerosis in Systemic Lupus Erythematosus: An Ongoing Challenge
}

\author{
Allison B Reiss*, Amy D Glass, David J Grossfeld, Heather A Renna, Daniel S Glass, Lora J Kasselman, Joshua De Leon and Steven E \\ Carsons
}

Department of Medicine and Winthrop Research Institute, NYU Winthrop Hospital, Mineola, NY 11501, USA

\begin{abstract}
Premature atherosclerotic cardiovascular disease (CVD) is a common and devastating complication of systemic lupus erythematosus (SLE, lupus) leading to myocardial infarction and stroke. Young women and men with systemic lupus erythematosus have strikingly high rates of coronary heart disease. Traditional risk factors do not fully explain the excessive cardiovascular events observed in SLE. During atherosclerosis, macrophage-driven inflammation leads to progressive damage characterized by accrual of lipid and fibrous elements in the vessel wall. Persistent immune system activation is likely key to acceleration of atherosclerosis in SLE, although SLE disease activity markers cannot predict cardiovascular risk, nor can Framingham risk factors. Strategies to treat and prevent CVD in lupus include statins and medications to control traditional CVD risk factors. However, these are insufficient with low success. While statins are a mainstay treatment for CVD in the general population, CVD in SLE is resistant to statins. This brief review explores the factors that set apart atherosclerotic CVD in lupus from the process in the general population.
\end{abstract}

\section{Introduction}

Systemic lupus erythematosus is a multisystem autoimmune rheumatic disease characterized by periods of exacerbation and remission [1] (Table 1). Breakdown of immunological self-tolerance manifests as autoantibody production and immune complex deposition. Both the innate and adaptive immune system are dysregulated. Autoantibody-producing B cells secrete inflammatory cytokines and, by presenting autoantigens, activate T cells [2]. Many organs can be affected, most commonly joints, skin, cardiovascular system, nervous system, kidneys and bone marrow [3]. SLE mainly affects young women during their childbearing years, and is found more commonly in minority populations $[4,5]$. Management is generally through the use of corticosteroids, antimalarials and immunosuppressive drugs [6,7] The human monoclonal antibody belimumab is specific for B-cell-activating factor, a B cell-regulating cytokine that is elevated in SLE. Belimumab is approved in the USA, Canada, Europe and other countries to treat adult SLE patients with mild-moderate active disease despite standard therapy [8].

Cardiovascular disease (CVD) causes significant excess morbidity and mortality in lupus patients relative to the general population [9-11]. Atherosclerotic CVD occurs earlier and more frequently in SLE, particularly in young women, a group normally relatively free of atherosclerosis [12-14]. Mortality from myocardial infarction in

Table 1. Systemic lupus erythematosus. General features

Systemic Lupus Erythematosus

Connective tissue related chronic inflammatory and autoimmune disorder

Immune complex and autoantibody-mediated tissue injury

Primarily affects pre-menopausal females

Heart, lungs, kidneys, joints are primary targets

Premature atherosclerotic CVD is the most common form of cardiovascular damage

Common symptoms: malar rash, fatigue, joint pain/swelling, headaches, anemia, fever
SLE is 10 times greater than in age-matched controls. Atherosclerosis contributes to about $30 \%$ of deaths in SLE and about $30 \%$ of lupus patients have subclinical atherosclerosis [15-17]. The dramatic excess in cardiovascular morbidity and mortality in young people with lupus is not explained by traditional risk factors or medication use.

\section{Explaining the Excess CVD Risk}

Lupus accelerates atherosclerosis, suggesting that immunologic factors impact atherogenesis in the autoimmune setting [18]. However, the precise pathophysiologic mechanism(s) that link SLE to atherosclerotic CVD are not known and SLE disease activity markers cannot predict CVD risk, nor can Framingham risk factors [19-21]. Known risk factors for atherosclerotic CVD that occur with greater frequency in SLE patients than in the general population include corticosteroid-induced hypercholesterolemia and hypertension associated with renal disease (Table 2). However, even in studies controlling for steroid therapy and renal disease, the association between SLE and accelerated atherosclerosis remains [21,22].

The pathogenesis of atherosclerosis involves interplay between cholesterol metabolism and cellular inflammatory pathways [23-25]. Persons with lupus exhibit elevated levels of cytokines, most notably type I interferons, and inflammatory mediators that can accelerate development of atherosclerosis by promoting cholesterol accumulation in macrophages and endothelial cells $[13,26,27]$. Lipid overload leads

*Correspondence to: Allison B. Reiss, Department of Medicine and Research Institute, NYU Winthrop Hospital, 101 Mineola Boulevard, Suite 4-004, Mineola, NY 11501, USA, Tel: 516-663-3455; E-mail: Allison.Reiss@NYULangone.org

Key words: lupus, atherosclerosis, statin, cholesterol

Received: January 20, 2019; Accepted: January 28, 2019; Published: January 31,2019 
to macrophage transformation into plaque-forming foam cell-a hallmark of atherosclerosis (Figure 1) [28]. In lupus, blood vessel inflammation results from autoimmunological endothelial activation [29]. Endothelial activation with breach of the monolayer, initiating factors in atherosclerosis, are associated with Type I interferons in SLE [30,31]. Activated endothelium expresses adhesion molecules, chemokines, and cytokines and recruits circulating monocytes in a multi-step process that involves sequential capture, rolling and adhesion, followed by transmigration and differentiation into macrophages.

Atherosclerosis in SLE, as in the general population, is histologically a disease of cholesterol accumulation in the arterial wall $[32,33]$. Current research focuses on the impact of inflammation and how it might be controlled. However, attempts to correlate CVD risk with autoimmune disease activity have been unsuccessful and, other than recognition of dyslipidemia as a risk factor, cholesterol metabolism has been largely ignored.

Routine lipid measurements do not distinguish between lupus and normal controls, nor do they help identify lupus patients with atherosclerosis [34]. LDL measurement is of limited value in CVD risk assessment for patients with SLE [35]. Lupus does cause disruptions in lipid metabolism and homeostasis, notably changes in quality of high density lipoprotein (HDL) with structural and functional abnormalities. Some studies show low circulating HDL levels as well [36,37]. Dysfunctional HDL that has lost its anti-inflammatory and atheroprotective properties has been observed in SLE [38].

Our group has used an in vitro cell culture approach to look at atherogenic properties of lupus plasma. We reported that cultured THP-1 human macrophages, a pertinent model of atherosclerosis, exposed to plasma from SLE patients manifest a pattern of disturbance

Table 2. Atherosclerotic risk factors in systemic lupus erythematosus. Traditional and nontraditional

\begin{tabular}{|c|l|}
\hline \multicolumn{2}{|c|}{ Atherosclerotic Risk Factors: Systemic Lupus Erythematosus } \\
\hline Traditional & \\
\hline Age & SLE-Traditional \\
\hline Sex & SLE disease duration \\
\hline Obesity & Cumulative damage \\
\hline Diabetes & Autoantibody levels \\
\hline Smoking & Inflammatory markers (cytokines, high sensitivity C-reactive protein) \\
\hline Hypertension & Use of steroids \\
\hline Hyperlipidemia & Use of cyclo-oxygenase inhibitors \\
\hline
\end{tabular}

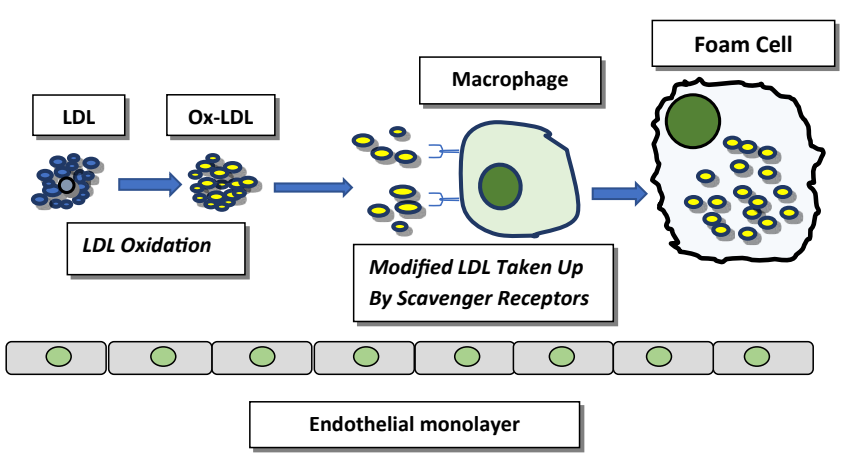

Figure 1. Foam cell formation. LDL particles (blue) become oxidized in the vascular wall. Oxidatively modified LDL (Ox-LDL, yellow) is then taken up by scavenger receptors on the macrophage cell surface. The internalized Ox-LDL accumulates inside the macrophage, transforming it into an atherogenic foam cell in expression of genes involved in lipid transport that is atheromapromoting. When THP-1 macrophages are exposed to lupus plasma, key proteins that prevent lipid overload are suppressed. These cholesterol efflux proteins are 27-hydroxylase and ATP binding cassette transporter (ABC)A1. In addition, the scavenger receptor CD36 that facilitates cholesterol uptake is augmented, leading to increased foam cell formation $[39,40]$. These results indicate that compared to healthy controls, SLE patients exhibit pro-atherogenic differences in cholesterol transport, encouraging lipid accumulation. Macrophage cholesterol homeostasis, a delicate balance among influx, endogenous synthesis, esterification/hydrolysis and efflux, is disrupted in the lupus environment, likely due to immune and inflammatory mediators and cytokines such as interferon- $\gamma[41,42]$.

While more advanced therapies have decreased mortality from lupus disease activity, deaths from atherosclerotic CVD in SLE have not declined [43]. An understanding of the underlying processes could lead to improved prediction of who among persons with lupus are at highest risk for developing CVD. At this time, prediction tools are lacking for the SLE population. Readily available assessments of atherosclerotic risk would be an invaluable tool for monitoring disease state and responsiveness to therapeutic interventions. McMahon, et al. [44] have assembled a biomarker Predictors of Risk for Elevated Flares, Damage Progression, and Increased Cardiovascular Disease in Patients with SLE (PREDICTS) based on proinflammatory HDL, plasma levels of leptin, homocysteine, and soluble TNF-like weak inducer of apoptosis as well as age, and diabetes. Even more recently, López, et al. [45] propose utilizing levels of anti-PON1 and anti-HDL antibodies in serum as biomarkers of endothelial damage and premature atherosclerosis in SLE. Imaging studies show some promise. Carotid artery Doppler ultrasound with measurement of both intima-media thickness and total plaque area, was shown to independently predict cardiovascular events [46-48]. Understanding pathogenesis and predicting risk are high priority so that effective interventions can be implemented [49].

\section{Current Treatment Approaches}

The traditional approach to atherosclerotic CVD therapy in SLE consists of lifestyle improvements and treatment of risk factors, mainly hypercholesterolemia. Drug regimens designed to lessen traditional risk factors may include antiplatelet agents, antihypertensives, anticoagulants, and, most commonly, statins [50,51]. Treatment with lipid-lowering statins, the first-line of therapy for atherosclerotic CVD is insufficient and cardiovascular morbidity and mortality in SLE patients remains inordinately high [52,53]. In the Lupus Atherosclerosis Prevention Study (LAPS), Petri, et al. [54] showed that the HMG CoA reductase inhibitor atorvastatin failed to reduce subclinical measures of atherosclerosis or disease activity over 2 years in SLE patients.

\section{Conclusions and the Future}

Our ability to predict who is at risk for CVD in the lupus population is limited and underestimated. Multiple aspects of the risk assessment and management program for atherosclerotic CVD in the general population do not work well in the SLE population. Our capacity to prevent development and progression of atherosclerosis is inadequate. Lifestyle modification and control of disease activity aimed at reducing inflammation are desirable, but insufficient. Despite optimal standard-of-care lipid lowering regimens, residual morbidity and mortality remains high. The value of statins is unclear, but appears to be less than in the general population. SLE is an independent risk factor for post-myocardial infarction mortality [55]. Unless new 
treatment approaches are developed, ASCVD is expected to cause an increasing proportion of the mortality in the lupus population.

\section{Acknowledgements}

The authors would like to thank Janet and Robert Buescher and The Elizabeth Daniell Research Fund.

\section{Conflict of Interest}

All authors have read the journal's authorship agreement and policy on disclosure of potential conflicts of interest and the authors declare no conflicts of interest.

\section{References}

1. Tsokos GC (2011) Systemic lupus erythematosus. N Engl J Med 365: 2110-2121. [Crossref]

2. Sanz I, Lee FE (2010) B cells as therapeutic targets in SLE. Nat Rev Rheumatol 6: 326-337. [Crossref]

3. Bruce IN, O'Keeffe AG, Farewell V (2015) Factors associated with damage accrual in patients with systemic lupus erythematosus: results from the Systemic Lupus International Collaborating Clinics (SLICC) Inception Cohort. Ann Rheum Dis 74: $1706-1713$

4. Pons-Estel GJ, Alarcón GS, Scofield L (2010) Understanding the epidemiology and progression of systemic lupus erythematosus. Semin Arthritis Rheum 39: 257-268.

5. Yen EY, Singh RR (2018) Brief Report: Lupus-An Unrecognized Leading Cause of Death in Young Females: A Population-Based Study Using Nationwide Death Certificates, 2000-2015. Arthritis Rheumatol 70: 1251-1255. [Crossref]

6. Dall'Era M, Bruce IN, Gordon C, Manzi S, McCaffrey J, et al. (2019) Current challenges in the development of new treatments for lupus. Ann Rheum Dis. [Crossref]

7. Tunnicliffe DJ, Singh-Grewal D, Kim S, Craig JC, Tong A (2015) Diagnosis, monitoring, and treatment of systemic lupus erythematosus: a systematic review of clinical practice guidelines. Arthritis Care Res (Hoboken) 67: 1440-1452.

8. Elalouf O, Keeling SO, Touma Z (2018) Subcutaneous belimumab in the treatment of systemic lupus erythematosus. Immunotherapy 10: 1163-1173. [Crossref]

9. Asanuma Y, Oeser A, Shintani AK, Turner E, Olsen N, et al. (2003) Premature coronaryartery atherosclerosis in systemic lupus erythematosus. N Engl J Med 349: 2407-2415.

10. Rua-Figueroa I, Arencibia-Mireles O, Elvira M, Erausquin C, Ojeda S, et al. (2010) Factors involved in the progress of preclinical atherosclerosis associated with systemic lupus erythematosus: a 2-year longitudinal study. Ann Rheum Dis 69: 1136-1139.

11. Abu-Shakra M, Novack V (2012) Mortality and multiple causes of death in systemic lupus erythematosus -- role of the death certificate. J Rheumatol 39: 458-460. [Crossref]

12. Hak AE, Karlson EW, Feskanich D, Stampfer MJ, Costenbader KH (2009) Systemic lupus erythematosus and the risk of cardiovascular disease: results from the nurses' health study. Arthritis Care and Research 61: 1396-1402.

13. Reiss AB (2009) Effects of inflammation on cholesterol metabolism: impact on systemic lupus erythematosus. Curr Rheumatol Rep 11: 255-260. [Crossref]

14. Roman MJ, Shanker BA, Davis A, Lockshin MD, Sammaritano L, et al. (2003) Prevalence and correlates of accelerated atherosclerosis in systemic lupus erythematosus. N Engl J Med 349: 2399-2406.

15. Lockshin MD, Salmon JE, Roman MJ (2001) Atherosclerosis and lupus: a work in progress. Arthritis Rheum 44: 2215-2217. [Crossref]

16. Bruce IN (2005) Atherogenesis and autoimmune disease: the model of lupus. Lupus 14: 687-690. [Crossref]

17. Wu GC, Liu HR, Leng RX, Li XP, Li XM, et al. (2016) Subclinical atherosclerosis in patients with systemic lupus erythematosus: A systemic review and meta-analysis. Autoimmun Rev 15: 22-37.

18. Nikpour M, Gladman DD, Urowitz MB (2013) Premature coronary heart disease in systemic lupus erythematosus: what risk factors do we understand? Lupus 22: 12431250. [Crossref]

19. Bruce IN (2005) Not only...but also': factors that contribute to accelerated atherosclerosis and premature coronary heart disease in systemic lupus erythematosus. Rheumatology (Oxford) 44: 1492-1502.
20. Svenungsson E, Jensen-Urstad K, Heimburger M, Silveira A, Hamsten A, de Faire U, Witztum JL, Frostegård J. Risk factors for cardiovascular disease in systemic lupus erythematosus. Circulation. 2001; 104:1887-1893.

21. Esdaile JM, Abrahamowicz M, Grodzicky T, Li Y, Panaritis C, et al. (2001) Traditional risk factors fail to fully account for accelerated atherosclerosis in systemic lupus erythematosus. Arthritis Rheum 44: 2331-2337.

22. Wilhelm AJ, Major AS (2012) Accelerated atherosclerosis in SLE: mechanisms and prevention approaches. Int J Clin Rheumtol 7: 527-539. [Crossref]

23. Wu MY, Li CJ, Hou MF (2017) New Insights into the Role of Inflammation in the Pathogenesis of Atherosclerosis. Int $J \mathrm{Mol} \mathrm{Sci}$ 18. [Crossref]

24. Ross R (1999) Atherosclerosis--an inflammatory disease. N Engl J Med 340: 115-126 [Crossref]

25. Lind L (2003) Circulating markers of inflammation and atherosclerosis. Atherosclerosis 169: 203-214. [Crossref]

26. Baechler EC, Batliwalla FM, Karypis G, Gaffney PM, Ortmann WA, et al. (2003) Interferon-inducible gene expression signature in peripheral blood cells of patients with severe lupus. Proc. Natl. Acad. Sci. U. S. A. 100: 2610-2615.

27. Okamoto A, Fujio K, Okamura T, Yamamoto K (2011) Regulatory T-cell-associated cytokines in systemic lupus erythematosus. J Biomed Biotechnol 2011: 463412.

28. Reiss AB, Cronstein BN (2012) Regulation of foam cells by adenosine. Arterioscler Thromb Vasc Biol 32: 879-886. [Crossref]

29. Mikolajczyk TP, Osmenda G, Batko B, Wilk G, Krezelok M, et al. (2016) Heterogeneity of peripheral blood monocytes, endothelial dysfunction and subclinical atherosclerosis in patients with systemic lupus erythematosus. Lupus 25: 18-27.

30. Lee PY, Li Y, Richards HB, Chan FS, Zhuang H, et al. (2007) Type I interferon as a novel risk factor for endothelial progenitor cell depletion and endothelial dysfunction in systemic lupus erythematosus. Arthritis Rheum 56: 3759-3769.

31. Yassin LM, Londono J, Montoya G (2011) Atherosclerosis development in SLE patients is not determined by monocytes ability to bind/endocytose Ox-LDL. Autoimmunity 44: 201-210.

32. Haider YS, Roberts WC (1981) Coronary arterial disease in systemic lupus erythematosus; quantification of degrees of narrowing in 22 necropsy patients (21 women) aged 16 to 37 years. Am J Med 70: 775-781. [Crossref]

33. Jain D, Halushka MK (2009) Cardiac pathology of systemic lupus erythematosus. $J$ Clin Pathol 62: 584-592. [Crossref]

34. Gonzàlez M, Ribalta J, Vives G, Iftimie S, Ferré R, et al. (2010) Nuclear magnetic resonance lipoprotein subclasses and the APOE genotype influence carotid atherosclerosis in patients with systemic lupus erythematosus. J Rheumatol 37: 22592267.

35. O'Neill SG, Pego-Reigosa JM, Hingorani AD, Bessant R, Isenberg DA, et al. (2009) Use of a strategy based on calculated risk scores in managing cardiovascular risk factors in a large British cohort of patients with systemic lupus erythematosus. Rheumatology (Oxford, England) 48: 573-575.

36. Lu L, Hu C, Zhao Y, He L, Zhou J, et al. (2018) Shotgun Lipidomics Revealed Altered Profiles of Serum Lipids in Systemic Lupus Erythematosus Closely Associated with Disease Activity. Biomolecules 8: pii: E105.

37. de Carvalho JF, Bonfá E, Borba EF (2008) Systemic lupus erythematosus and "lupus dyslipoproteinemia". Autoimmun Rev 7: 246-250.

38. McMahon M, Grossman J, FitzGerald J (2006) Proinflammatory high-density lipoprotein as a biomarker for atherosclerosis in patients with systemic lupus erythematosus and rheumatoid arthritis. Arthr Rheum 54: 2541-2549.

39. Reiss AB, Anwar K, Merrill JT, Chan ES, Awadallah NW, et al. (2010) Plasma from systemic lupus patients compromises cholesterol homeostasis: a potential mechanism linking autoimmunity to atherosclerotic cardiovascular disease. Rheumatol Int 30: 591598.

40. Reiss AB, Wan DW, Anwar K, Merrill JT, Wirkowski PA, et al. (2009) Enhanced CD36 scavenger receptor expression in THP-1 human monocytes in the presence of lupus plasma: linking autoimmunity and atherosclerosis. Exp Biol Med 234: 354-360.

41. Reiss AB, Awadallah N, Malhotra S, Montesinos MC, Chan ESL, et al. (2001) Immune complexes and interferon-? decrease cholesterol 27-hydroxylase in human arterial endothelium and macrophages. J Lipid Res 42: 1913-1922.

42. Reiss AB, Patel CA, Rahman MM, Chan ES, Hasneen K, et al. (2004) IFN-? impedes reverse cholesterol transport and promotes foam cell transformation in THP-1 human monocytes/macrophages. Med Sci Monit 10: BR420-425. 
43. Bernatsky S, Boivin JF, Joseph L, Manzi S, Ginzler E, et al. (2006) Mortality in systemic lupus erythematosus. Arthritis Rheum 54: 2550-2557.

44. McMahon M, Skaggs BJ, Grossman JM, Sahakian L, Fitzgerald J, et al. (2014) A panel of biomarkers is associated with increased risk of the presence and progression of atherosclerosis in women with systemic lupus erythematosus. Arthritis Rheumatol 66: 130-139.

45. López P, Rodríguez-Carrio J, Martínez-Zapico A, Pérez-Álvarez ÁI, López-Mejías R, et al. (2017) Serum Levels of Anti-PON1 and Anti-HDL Antibodies as Potential Biomarkers of Premature Atherosclerosis in Systemic Lupus Erythematosus. Thromb Haemost 117: 2194-2206

46. 46. Eder L, Gladman DD, Ibañez D, Urowitz MB. The correlation between carotid artery atherosclerosis and clinical ischemic heart disease in lupus patients. Lupus 23: $1142-1148$.

47. Kao AH, Lertratanakul A, Elliott JR, Sattar A, Santelices L, Shaw P, et al. Relation of carotid intima-media thickness and plaque with incident cardiovascular events in women with systemic lupus erythematosus. Am J Cardiol 112: 1025-1032.

48. Polak JF, O'Leary DH (2016) Carotid Intima-Media Thickness as Surrogate for and Predictor of CVD. Glob Heart 11: 295-312. [Crossref]
49. Haque S, Skeoch S, Rakieh C, Edlin H, Ahmad Y, et al. (2018) Progression of subclinical and clinical cardiovascular disease in a UK SLE cohort: the role of classic and SLE-related factors. Lupus Sci Med 5: e000267.

50. McMahon M, Skaggs B (2014) Pathogenesis and treatment of atherosclerosis in lupus Rheum Dis Clin North Am 40: 475-495 [Crossref]

51. Iaccarino L, Bettio S, Zen M, Nalotto L, Gatto M, et al. (2013Premature coronary heart disease in SLE: can we prevent progression? Lupus 22:1232-1242.

52. Fatemi A, Moosavi M, Sayedbonakdar Z, Farajzadegan Z, Kazemi M, et al. (2014) Atorvastatin effect on systemic lupus erythematosus disease activity: a double-blind randomized clinical trial. Clin Rheumatol 33: 1273-1278.

53. Stojan G, Petri M (2013) Atherosclerosis in systemic lupus erythematosus. J Cardiovasc Pharmacol 62: 255-262. [Crossref]

54. Petri MA, Kiani AN, Post W, Christopher-Stine L, Magder LS (2011) Lupus Atherosclerosis Prevention Study (LAPS). Ann Rheum Dis 70: 760-765.

55. Lin CY, Shih CC, Yeh CC, Chou WH, Chen TL, et al. (2014) Increased risk of acute myocardial infarction and mortality in patients with systemic lupus erythematosus: two nationwide retrospective cohort studies. Int J Cardiol 176: 847-851.

Copyright: $\odot 2019$ Reiss AB. This is an open-access article distributed under the terms of the Creative Commons Attribution License, which permits unrestricted use, distribution, and reproduction in any medium, provided the original author and source are credited. 